\title{
The Treatment of Primary Urethral Carcinoma - the Dilemmas of a Rare Condition: Experience with Partial Urethrectomy and Adjuvant Chemotherapy
}

\author{
O.W. Hakenberg H.-J. Franke M. Froehner M.P. Wirth \\ Klinik und Poliklinik für Urologie, Universitätsklinikum Carl-Gustav Carus, Dresden
}

Key Words

Urethra · Urethral neoplasms · Surgical therapy ·

Chemotherapy

\section{Summary}

Background: Primary urethral carcinoma is a very rare condition, and no large-scale experience with such cases has been published. Treatment will therefore have to follow rules established for the treatment of similar conditions. Patients: Six cases of primary urethral carcinoma ( 5 male, 1 female) who had been treated at our institution between 1995 and 1999 were retrospectively analyzed. In 3 male cases, a primary urothelial carcinoma of the distal urethra was treated by distal urethrectomy only. In 3 other cases with locally advanced tumors and/or lymph node metastases surgical treatment was followed by adjuvant cisplatinum-containing chemotherapy. Results: In the 3 cases with distal urethral carcinoma, partial urethrectomy with preservation of the penis resulted in cure, with a follow-up of 12-71 months. In the cases with advanced disease, adjuvant chemotherapy after surgery has resulted in complete remissions in all 3 cases, with a followup of 4-47 months at present. Conclusions: In localized, noninvasive carcinoma of the distal male urethra, partial urethrectomy seems adequate and the avoidance of penile amputation justified. In advanced cases, after local excision and lymphadenectomy adjuvant chemotherapy which by necessity must follow the guidelines established for the treatment of other urothelial or squamous cell malignancies seems to be beneficial.
Schlüsselwörter

Urethra - Urethrakarzinom - OperativeTherapie · Chemotherapie

\section{Zusammenfassung}

Hintergnund: Das primäre Harnröhrenkarzinom ist eine sehr seltene Erkrankung, und in der Literatur gibt es keine prospektiven Serien mit größeren Fallzahlen. Die Behandlung wird sich daher an Erfahrungen orientieren müssen, die bei der Behandlung ähnlicher Krankheitsbilder gewonnen wurden. Patienten: Sechs Fälle von primärem Urethralkarzinom (5 Männer, 1 Frau), die zwischen 1995 und 1999 in unserer Klinik behandelt wurden, wurden retrospektiv analysiert. Bei 3 der männlichen Patienten lag ein primäres Urothelkarzinom der distalen Harnröhre vor, und es wurde eine Urethrateilresektion ohne adjuvanteTherapie durchgeführt. In den 3 anderen Fällen mit lokal fortgeschrittenen Tumoren und/oder Lymphknotenbefall wurde nach operativer Behandlung eine adjuvante Cisplatin-haltige Chemotherapie durchgeführt. Ergebnisse: In allen 3 Fällen nach Urethrateilresektion wurde eine komplette Heilung bei einer Nachbeobachtung von 12-71 Monaten erzielt. Bei den fortgeschrittenen Fällen mit lymphogener Metastasierung wurde nach adjuvanter Chemotherapie in allen 3 Fällen eine komplette Remission bei einer Nachbeobachtung von bislang 4-47 Monaten erzielt. Schlußfolgenungen: Beim lokalisierten, nichtinvasiven distalen Urethralkarzinom des Mannes ist eine organerhaltende Strategie gerechtfertigt. In lokal fortgeschrittenen und/oder lymphogen metastasierten Fällen ist nach lokaler Exzision und Lymphadenektomie eine adjuvante Chemotherapie, die sich an den Erfahrungen der Behandlung von anderen Plattenepithel- und Urothelkarzinomen orientieren muß, sinnvoll und erfolgversprechend.

\begin{tabular}{ll}
\hline KARGER & ○ $2001 \mathrm{S.K}$ arger G mbH , Freiburg \\
Fax +497614520714 & A ccessible online at: \\
$\begin{array}{l}\text { E-mail Information@K arger.de } \\
\text { www.karger.com }\end{array}$ & www.karger.com/journals/onk
\end{tabular}

Dr. Oliver Hakenberg

K linik und Poliklinik für U rologie

U niversitätsklinikum Carl-G ustav Carus

Fetscherstraße 74, D-01307 D resden (G ermany)

Tel. +49 351 458-2447, Fax - 4333

E-mail hakenberg@debitel.net 


\section{Introduction}

Primary carcinoma of the urethra is a rare condition. O nly approximately 600 cases have been reported in males [1] and about 1,200 cases in females [2]. H owever, although the true incidence of urethral cancer is unknown, it is probably higher than the number of cases reported in the literature suggests. $U$ rethral carcinoma represents the only exception to the rule that shared genitourinary malignancies are more common in men than in women. Classification of urethral carcinoma is done according to the location and histology of the epithelium lining the urethra [3].The majority of cases represent squamous cell carcinoma, and patients are generally above 50 years of age on presentation.

In males, primary carcinomas of the urethra occur most often in the bulbomembranous urethra $(60 \%)$, while its location in the penile $(30 \%)$ or prostatic urethra $(10 \%)$ is less common. The vast majority $(78 \%)$ are squamous cell carcinomas and only $15 \%$ transitional cell carcinomas. The remainder $(6 \%)$ represent the very rare variant of urethral adenocarcinoma [4]. In females, 55\% represent squamous cell carcinoma, 17\% transitional cell carcinoma and $16 \%$ adenocarcinoma [5].

The etiology and pathogenesis of urethral carcinoma are essentially unknown although probable associated factors have been identified. The single most important factor for the prognosis of urethral cancer seems to be its location and extent at diagnosis and hence its amenability to surgical control. While symptoms and signs of early urethral cancer are nonspecific in both sexes, tumors of the posterior urethra tend to be diagnosed at a later stage and, for this reason and because their radical excision is more invasive and complicated, carry an unfavorable prognosis.

B ecause urethral carcinoma is very rare, no single institution has enough patients to prospectively analyze different treatment options. For this reason, experience with different surgical treatment options is empirical and often anecdotal.

We report our experience with 6 cases of primary urethral carcinoma in our institution.

\section{Patients and Case Histories}

Six cases of primary urethral cancer, 5 in males and 1 in a female, were diagnosed and treated at our institution between 1995 and 1999. A II cases suffered from primary urethral carcinoma and, after histological confirmation of urethral carcinoma and extensive clinical staging, were without any history or evidence of other malignancies of the urinary tract.

\section{Case 1}

A 63-year-old man had been suffering from persistent and pronounced alguria for 6 months. A suspicious papillomatous lesion was seen on urethroscopy in the distal penile urethra which was biopsied. $\mathrm{H}$ istology confirmed a transitional cell carcinoma. A fter full diagnostic evaluation without any evidence of other sites of transitional cell carcinoma in the urinary tract, an organ-preserving distal urethrectomy with negative surgical margins was performed. Tumor stage was PT $2 \mathrm{G} 3$. No adjuvant treatment was given and the patient is free of recurrence 27 months after surgery.

Case 2

A 58-year-old male presented with acute epididymitis when a small papillomatous lesion resembling condylomata acuminata was seen pro- truding from the fossa navicularis of the urethra. The lesion was biopsied and destroyed by laser application. $\mathrm{H}$ istology revealed transitional cell carcinoma (pTa G 2), and human papilloma virus type 16 (H PV-16) was found in a postoperative urethral swab by polymerase chain reaction. A n extensive diagnostic work-up including urinary cytology, transurethral bladder biopsies and all relevant radiological examinations revealed no evidence of other malignant lesions. For definitive surgical treatment an organ-preserving distal urethrectomy was performed. The patient has been recurrence-free for 5 years and 11 months.

Case 3

A 57-year-old man had noticed a slowly progressive nontender left-sided inguinal swelling for 1 year. He presented 2 weeks after the onset of recurrent macrohematuria. U rethrocystoscopy showed exophytic papillomatous lesions of the distal penile urethra, and biopsy confirmed transitional cell carcinoma. A gain, no evidence of transitional cell carcinoma at other sites of the urinary tract was found, and distal urethrectomy of a pT 1 G 2 lesion was performed with negative surgical margins. Bilateral inguinal lymphadenectomy revealed unilateral metastatic disease ( $p N 2)$. Two courses of an adjuvant polychemotherapy with the MVEC regimen (methotrexate, vinblastine, etoposide and cisplatinum) were given. The patient is without evidence of disease 12 months after the cessation of chemotherapy.

Case 4

A 74-year-old man had noticed a palpable induration of the distal penis This was initially suspected to represent Peyronie's disease by his physician. On local progression and the development of alguria the patient was referred 10 months after the initial presentation. U rethrocystoscopy showed fragile papillomatous lesions in the distal urethra, and cytology and biopsy confirmed transitional cell carcinoma. Due to extensive infiltration of both cavernous bodies a complete penile amputation was performed with complete removal of the local lesion ( $p T 3 G 3$ ). No inguinal lymphadenopathy was clinically seen, but on M RI enlarged lymph nodes were noticed. Bilateral inguinal lymphadenectomy revealed unilateral metastatic lymph node disease ( $\mathrm{pN} 2$ ). Further staging evaluation gave no evidence of other metastatic lesions. A djuvant chemotherapy with 2 courses of M VEC was given, which was poorly tolerated by the patient. Pancytopenia developed during the 2nd cycle which was prematurely terminated. A fter full recovery, 2 courses of a regimen consisting of paclitaxel monotherapy were given and well tolerated. The patient has been without evidence of disease since the cessation of chemotherapy for 12 months.

Case 5

A 51-year-old woman with a history of breast cancer treated successfully surgically with adjuvant radiotherapy 18 years previously presented with a nontender swelling at the external urethral meatus which she had noticed herself. On examination a whitish induration and enlargement of the meatus of about $1 \mathrm{~cm}$ in diameter was seen, which on urethroscopy covered the distal urethra for about $4 \mathrm{~mm}$ while the upper urethra and the urinary bladder appeared normal. A biopsy revealed squamous cell carcinoma. D istal urethrectomy was performed ( $\mathrm{PT} 2 \mathrm{G} 2$ ), however, with a positive surgical margin. A t the time, the patient refused further treatment. 5 months later inguinal lymphadenopathy was noted, and bilateral inguinal lymphadenectomy was performed which revealed unilateral metastatic disease. 5 courses of polychemotherapy with methotrexate, bleomycin, and cisplatinum according to the regimen described by D exeus et al. [6] were given and well tolerated. The patient has been free of recurrence for 3 years and 11 months.

\section{Case 6}

A 54-year-old man suffering from recurrent bulbous urethral strictures was referred for urethroplasty. Previously, the patient had undergone internal urethrotomies for recurrent strictures 3 times in 2 years. A fter evaluation for the extent of the stricture, onlay urethroplasty with a buccal mucosal graft was performed. The postoperative course was uncomplicated, and the patient discharged free of urinary symptoms with a full urinary stream. 
The patient presented again 6 months later with alguria, poor stream, and a tender bulbous urethra. A fter suprapubic catheter drainage, further evaluation showed a narrowing of the bulbous urethra by partially necrotic whitish tissue. Biopsy revealed squamous cell carcinoma. Surgical resection of the bulbous urethra and the prostate via the perineal route were done with histopathological evidence of incomplete resection. Three courses of adjuvant chemotherapy with bleomycin, methotrexate and cisplatinum were given and well tolerated. The patient is at present in remission 4 months after second-line chemotherapy with paclitaxel and carboplatin.

\section{Results}

In the 3 cases of localized carcinoma of the distal urethra in men (cases 1-3), partial urethrectomy with preservation of the penile organ resulted in $100 \%$ survival without adjuvant treatment. A II 3 patients are without evidence of disease with a follow-up ranging from 12 to 71 months.

In the cases with locally advanced tumor and/or lymph node metastases treatment with surgical excision (complete resection with penile amputation in 1 case, incomplete resection in 1 male and 1 female case) and adjuvant chemotherapy has resulted in complete remissions in all 3 cases with a follow-up ranging between 4 and 47 months so far. In the case after urethroplasty (case 6), although the patient is at present without evidence of disease, progression must be expected while adjuvant chemotherapy has resulted in significant progression-free survival in the two other cases.

\section{Discussion}

The etiology of urethral carcinoma is essentially unknown in both genders although associations with probable etiological factors have been identified. In men these are urethral stricture, a history of venereal disease, and urethritis. A history of previous or coexisting urethral stricture has been reported in $35 \%$ [7], $48 \%$ [8] and $88 \%$ [9] of cases of primary male urethral carcinoma. In the series of R ay et al. [8], a history of venereal disease was noted in $44 \%$ of men with primary urethral carcinoma. In women, urethral caruncle, diverticula, and chronic or recurrent lower urinary tract infections have been implicated as predisposing factors for the development of urethral cancer although the associations are weak [10, 11].

H PV -16 has been found in both primary and metastatic lesions of 4 of 14 cases of primary male urethral carcinoma [12], thus providing evidence that this virus is a likely etiologic factor in primary squamous cell carcinoma of the urethra in males. $\mathrm{No}$ similar association of HPV with urethral cancer has been reported for women.

B ecause primary urethral carcinoma is such a rare condition, reports in the literature consist only of small-scale retrospective analyses and case reports. D ue to the low number of patients treated with this condition, there are no prospective trials analyzing different treatment options. $\mathrm{H}$ ence, treatment decisions will by necessity have to be based on the personal experience of a few cases and the published experience of small groups of patients. Transitional cell carcinoma of the prostatic urethra and the prostate is not discussed here as it represents a different disease entity which should be treated by radical cystoprostatectomy and urethrectomy [13].
G enerally, for primary urethral carcinoma excision of the lesion with surgical local control of the disease is and must be the first treatment option. Primary radiotherapy has been reported in case reports [14] with following local recurrence, and there is no valid evidence to support the use of radiotherapy in cases where curative surgical treatment is possible. With surgical treatment, the extent of the procedure for the treatment of primary urethral carcinoma in males is not defined. A Iso the role of lymphadenectomy in distal urethral cancer is completely undefined, and lastly there are no valid guidelines for the chemotherapeutic management of metastatic urethral cancer.

The cases reported here illustrate these dilemmas of treatment decisions that must be made in such cases and also represent some unusual points of urethral carcinoma. First, although urethral cancer is more common in women, we have seen more male patients with this condition. Secondly, the 3 cases with localized distal urethral carcinoma all had transitional cell carcinoma which is unusual (cases 1-3). The finding of HPV-16 in association with transitional cell carcinoma of the urethra is also unusual (case 2) and may be coincidental.

The symptoms and signs of urethral cancer are nonspecific, and in males the diagnosis tends to be delayed for this reason (case 4). A high degree of suspicion is required in cases of recurrent bulbous urethral strictures (case 6), especially if these are difficult to treat and have a tendency to bleed profusely with dilatation or internal urethrotomy [2]. The association of squamous cell urethral carcinoma and recurrent bulbous urethral strictures is well supported by retrospective analysis (see above) although not undisputed. M andler et al. [15] reported only a $16 \%$ previous history of urethral strictures in males with urethral carcinoma, and in a series of 280 cases of urethroplasty performed for strictures only 1 patient had a urethral carcinoma [16]. I is thus not entirely clear whether the reported associations of the rare primary urethral carcinoma in males with the very common entities of urethral stricture, previous history of sexually transmitted disease, and urethritis are causative in nature.

$14-30 \%$ of male and female patients with urethral malignancy will have lymph node spread at diagnosis [8, 17]. Inguinal lymphadenopathy in urethral cancer (case 3) suggests metastatic disease with a high probability [18]. A high degree of suspicion is required even if no palpable lymph nodes are present, and staging examinations with a high sensitivity in detecting nonpalpable inguinal lymph node enlargement such as M R I may be advisable (case 4).

There is no universally accepted clinical staging system for urethral malignancy. For male urethral cancer the system proposed by R ay and Guinan [8] (with stages $0, A, B, C$ and D 1 and $D 2$ ) has been used in the USA and was later replaced by the system proposed by the A merican Joint Committee on Cancer which is identical to the TNM system of the U ICC used in E urope [19].

In primary carcinoma of the distal urethra in males the treatment options described in the literature are varied and range from transurethral resection of the lesion, open resection with end-to-end anastomosis [20], partial penile amputation and complete penile amputation to full emasculisation [21].

A s in penile carcinoma, the conflicting issues of surgical disease control versus organ preservation are often difficult to combine 
[22]. While simple transurethral resection of a carcinomatous urethral lesion seems inadequate and not advisable, preservation of the penis with partial urethrectomy is appropriate in cases of superficial $(\mathrm{Ta}, \mathrm{T} 1)$ distal urethral carcinoma in males. With such a procedure, the glans and corpora cavernosa and thus the main components, and function of the penile organ are preserved while a midshaft artificial hypospadia is created, allowing uninhibited voiding. The 3 cases with distal transitional cell urethral carcinoma we treated in this manner (cases 1-3) were satisfied and are recurrence-free.

Thus, while in our opinion it is essential to provide safe and adequate surgical control of the disease it is of equal importance to avoid surgical over-treatment with complete penile amputation which can have debilitating consequences for some men.

A dvanced disease with metastatic lymph node spread must be surgically explored by inguinal lymphadenectomy which must be considered to have mainly diagnostic value. B ilateral groin dissection still carries a high risk of complications and associated morbidity in large series of penile cancer patients [23-25]. The role of prophylactic lymphadenectomy in urethral cancer is not defined. Lymphadenectomy is undisputably indicated in cases of enlarged nodes and suspected metastatic disease (cases 3-5).

$\mathrm{H}$ owever, removal of metastatic inguinal lymph nodes cannot be considered to be curative, and histological proof of lymph node involvement necessitates systemic therapy although distant metastastic spread seems to be a late occurrence in urethral cancer. Since there are no trials of chemotherapy for urethral carcinoma, the regimens employed will have to be those employed for histologically similiar tumor entities at other sites. Thus, for transitional cell carcinoma of the urethra, MVEC or MVA C regimens are used, with the options to use gemcitabine or paclitaxel as second-line treatments (case 3 and 4). For squamous cell carcinoma of the urethra, we have used regimens following the recommended treatment for metastatic squamous cell carcinoma of the penis (cases 5 and 6). The chemotherapy described by Dexeus et al. $[6,26]$ is the most commonly used treatment regimen for this purpose. H owever, the rationale for using this regimen is also based on a very small group of patients.

Incomplete resection of the tumor due to advanced local disease carries a poor prognosis (cases 5 and 6 ). With the difficulties of complete resection encountered in female urethral cancer when radical cystourethrectomy is not done, and in carcinoma of the proximal bulbous male urethra, rapid disease progression is likely. When surgical control of the disease is not possible, systemic chemotherapy is indicated and should be undertaken as soon as possible.

Thus in females with urethral cancer, radical surgical treatment with complete urethrectomy or cystourethrectomy plus urinary diversion must be considered as local excision even of distal urethral carcinoma carries a high risk of progression. In the case described (case 5), however, inguinal metastases following incomplete resection (R 1 ) of the primary tumor were successfully treated by lymphadenectomy and adjuvant chemotherapy.

In the rare case of a carcinoma developing after urethroplasty radical surgical excision is difficult and oncologically probably not feasible (case 6). It is possible that in this case squamous cell carcinoma of the urethra had been present as the underlying cause of the recurrent bulbous strictures and went undetected at the time of urethroplasty. Thus, a high degree of suspicion is warranted and perhaps routine histological examination in cases of recurrent bulbous strictures advisable.

B ecause of the rarity of urethral carcinoma, attempts to develop standardized treatment based on prospective studies have been unsuccessful [27]. For this reason definite and evidencebased recommendations are not available. Thus, the role of radiotherapy in the treatment of this disorder is largely undefined. In low-stage disease of the female urethra interstitial radiation therapy has resulted in cure rates of $60-80 \%[28,29]$. In more advanced stages of female urethral carcinoma where radical therapy is required, reported 5-year survival rates after radiotherapy vary between 0 and $57 \%[5,14,30,31]$ compared to those after surgery of $10-17 \%$ [32]. Preoperative radiotherapy followed by anterior exenteration has resulted in 5-year survival of around 50\% in small series [31, 33, 34].

In male urethral cancer, most authors agree that surgical excision remains the preferred mode of treatment. $R$ adiotherapy has therefore been reserved mainly for patients who have failed local control or have refused surgical treatment. The reported radiotherapy results have thus been disappointing [27]. H owever, there may be a role for radiotherapy in male urethral carcinoma in combination with chemotherapy for downstaging of locally advanced lesions before surgical resection [35].

The role of lymphadenectomy in patients with suspected lymph node disease is undisputed. However, adjuvant treatment options in patients with lymph node disease is undefined. Different institutions undertake different efforts to develop new modalities of treatment, including combination radiotherapy, chemotherapy and surgery. We believe that adjuvant chemotherapy is certainly indicated when lymph node disease is seen as this is likely to represents systemic rather than regional disease only.

The prognosis of urethral cancer in localized disease with complete surgical resection is good while that of advanced disease remains poor. The overall survival of all stages is around $50 \%$, but only $5-15 \%$ for posterior tumors [7, 21, 36, 37]. For urethral carcinoma in females as well as for posterior urethral lesions in males, the prognosis is less good than for anterior urethral lesions in males. A $100 \%$ disease-free and disease-specific survival rate has been reported for male patients with carcinoma originating in the fossa navicularis, comparing to $55 \%$ for penile urethral and $25 \%$ for bulbomembranous urethral carcinomas. These data and our own experience support that complete surgical control must be the first treatment goal and that organ-preserving surgery in male anterior urethral carcinoma is justified. The considerably worse prognosis of male posterior and female urethral carcinoma necessitates more aggressive surgery. The poor prognosis of metastatic disease in our view requires systemic treatment and thus polychemotherapy.

\section{Conclusions}

Primary urethral carcinoma as a rare condition represents a challenge to the urologic surgeon since, due to the lack of 
clinical trials, no valid treatment guidelines based on large-scale experience are available. $R$ adical surgical treatment is the first treatment option. 0 rgan preservation in distal urethral carcinoma in males is feasible and justified. $U$ rethral carcinoma in females and proximal urethral carcinoma in males requires a much more invasive and radical surgical approach. Staging should include radiological evaluation for inguinal and pelvic lymph node spread, and bilateral lymphadenectomy should be undertaken if suspicious findings are seen. A dvanced and metastatic disease can be treated by adjuvant chemotherapy but carries a poor prognosis.

\section{References}

$1 \mathrm{H}$ err H W: Surgery of penile and urethral carcinoma; in Walsh PC, Retik A B, Darracott Vaughan E J r Wein AJ (eds): Campbell's U rology. Philadelphia, Saunders, 1998, pp 3395-3409.

2 Poore RE, M cCullough D L: U rethral carcinoma; in Gillenwater JY, G rayhack JT, H owards SS, D uckett JW (eds): A dult and Pediatric U rology. St. Louis, M osby, 1996, pp 1837-1852.

3 M ostafi FK, D avis CI, Sesterhenn IA : Carcinoma of the male and female urethra. U rol Clin North A m 1992;19:347-358.

4 Sullivan J, G rabstald $\mathrm{H}$ : M anagement of carcinoma of the urethra; in Skinner D G, D eK ernion JB (eds) G enitourinary Cancer. Philadelphia, Saunders, 1978, pp 419.

$5 \mathrm{~N}$ arayan $\mathrm{P}$, Konety B : Surgical treatment of female urethral carcinoma. U rol Clin North A m 1992; 19:373.

6 Dexeus $F H$, Logothetis CJ, Sella A, A mato $R$, K ilbourn A, Fitz K, Striegel A : Combination chemotherapy with methotrexate, bleomycin and cisplatin for advanced squamous cell carcinoma of the male genital tract. J U rol 1991;146:1284-1287.

7 K aplan G W, B uckley GJ, G rayhack J T: Carcinoma of the male urethra. J U rol 1967;98:365-371.

$8 \mathrm{R}$ ay $\mathrm{B}, \mathrm{C}$ anto S, Whitmore WF: Experience with primary carcinoma of the male urethra. J U rol 1977;117:591-594

$9 \mathrm{H}$ otchkiss RS, A melar RD: Primary carcinoma of the male urethra. J U rol 1954;72:1181.

$10 \mathrm{M}$ arshall FC, U son AC, M elicow M M : Neoplasms and caruncles of the female urethra. Surg $G$ ynecol O bstet 1960;110:723-733.

11 Rajan N, Tucci P, Mallouh C, Choudhury M : Carcinoma in female urethral diverticulum: Case reports and review of management. J U rol 1993;150: 1911-1914.

12 Wiener J S, Liu ET, Walther PJ : O ncogenic human papilloma virus type 16 is associated with squamous cell cancer of the male urethra. Cancer R es 1992;52 5018-5023.

13 Zincke $\mathrm{H}, \mathrm{U}$ tz DC, Farrow GM : R eview of Mayo Clinic experience with carcinoma in situ. U rology 1985;26(suppl 4):39-46.

14 Bracken R B, Henry R, Ordonez N : Primary carcinoma of the male urethra. South Med J 1980;73: 1003-1005.

$15 \mathrm{M}$ andler J I, Pool TL : Primary carcinoma of the male urethra. J U rol 1966;96:67-72.

16 Colapinto V, E vans D H : Primary carcinoma of the male urethra developing after urethroplasty for stricture. J U rol 1977;118:581-584.

17 A nderson KA, M CA ninch JW: Primary squamous cell carcinoma of the anterior male urethra. $U$ rology 1984;23:134-146.

$18 \mathrm{E}$ berle J: Harnröhrenkarzinome; in Rübben $\mathrm{H}$, (H rsg): U roonkologie. Heidelberg, Springer, 1997, pp 565-574.
19 Beahrs $\mathrm{OH}$ : M anual for Staging of Cancer, 4 ed. Philadelphia, Lippincott, 1992.

20 L evine R L : U rethral cancer. Cancer 1980;45(suppl 7): 1965-1972.

21 Dinney PN, Johnson DE, Swanson A, Babaian RJ, von Eschenbach AC: Therapy and prognosis for male anterior urethral carcinoma. U rology 1994;43: 506-514.

$22 \mathrm{H}$ akenberg OW, Wirth M P: I ssues in the treatment of penile carcinoma. A short review. U rol Int 1999;62:229-233.

23 Ornellas A A, Seixas A L C, M arota A, Wisnescky A, Campos $F$, de Moraes JR: Surgical treatment of invasive squamous cell carcinoma of the penis: Retrospective analysis of 350 cases. J U rol 1994; 151:1244-1249.

$24 \mathrm{R}$ avi $\mathrm{R}$ : M orbidity following groin dissection for penile carcinoma. B J J U rol 1993;72:941-945.

$25 \mathrm{M}$ artin $\mathrm{M}$ artinez J C, Herranz A mo $\mathrm{F}$, Jara R ascon C, Subira Castrillon C, Gonzales Chamorro F, Hernandez Fernandez $\mathrm{C}$ : Complications of inguinal lymphadenectomy for penile carcinoma. Origin, management and prevention. A ctas U rol Esp 1995:19:759-771.

26 D exeus F, Logothetis C, Sipahi H: Chemotherapy for advanced squamous carcinoma of the male external genital tract and urethra; in Carlton CE (ed.): Controversies in U rology. Chicago, Y ear B ook M edical, 1990, pp 255-259.

27 Terry PJ, Sarosdy MF : U rethral carcinoma in the male and female: Management and prognosis; in O esterling JE, R itchie JP (eds): U rologic O ncology. Philadelphia, Saunders, 1997, pp 572-578.

28 Skinner E C, Skinner DJ, M anagement of carcinoma of the female urethra; in Skinner D G, L ieskovsky G (eds): D iagnosis and $M$ anagement of $G$ enitourinary Cancer. Philadelphia, Saunders, 1988, pp 492-497.

$29 \mathrm{G}$ rabstald $\mathrm{H}$ : Tumours of the urethra in men and women. Cancer 1973;32:1236-1255.

30 A ntoniades J: Radiotherapy in carcinoma of the female urethra. Cancer 1969;42:70-76.

$31 \mathrm{H}$ ahn $\mathrm{P}, \mathrm{K}$ repant $\mathrm{G}, \mathrm{M}$ alaker $\mathrm{K}$ : Carcinoma of the female urethra: The $M$ anitoba experience. $U$ rology 1991;37:106-109.

32 B racken RB: Exenterative surgery for posterior urethral cancer. U rology 1982;19:248-251.

33 J ohnson DE, O 'Connell JR: Primary carcinoma of the female urethra. U rology 1983:42-45.

$34 \mathrm{~A}$ li M M, K lein FA, H azra TA : Primary female urethral carcinoma: A retrospective comparison of different treatment techniques. Cancer 1988;62:54-57.

35 Baskin LS, Turzan C: Carcinoma of the male urethra: $M$ anagement of locally advanced disease with combined chemotherapy, radiotherapy and penile preserving surgery. U rology 1992;39:21-25.

36 Sarosdy MF: U rethral carcinoma. AUA Update Service 1987;7:2-7.

37 H opkins SC, Nag SK, Soloway M S, Primary carcinoma of the male urethra. U rology 1984;23:128-133. 